\title{
Miscellany
}

\section{World Mental Health Day}

As part of the activities surrounding World Mental Health Day this year (10th October, 1995), the President, Dr Fiona Caldicott, planted an "amber gum" tree in Belgrave Square. To celebrate this Day, there were a number of "plantings" going on throughout the country. The College's ceremony was a small but intimate affair which many of our neighbours attended. The theme for this year's Day was mental health problems in young people and on a more serious note, the College launched a new factsheet for the general public on Severe and Chronic Mental Disorders in Children and Young People.

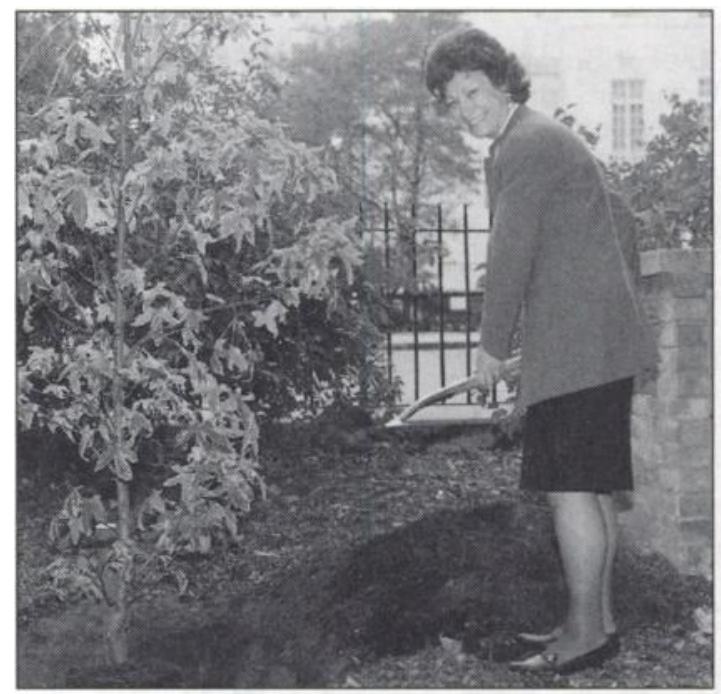

\section{New publications}

Medical Aspects of Fitness to Drive - A Guide for Medical Practitioners (5th edn) edited by J. F. Taylor, Chairman of the Transport Committee of the Medical Commission on Accident Prevention. This book describes the legal provisions and medico-legal considerations and also deals with clinical disorders, ageing and alcohol and drug abuse. The Department of Transport has agreed to supply complimentary copies to Members of the College. Any member wishing to obtain a copy should contact the Book Sales Assistant, Kerstin Sayoud (Tel: 0171-235 2351, extension 146).

Could this be Autism by the National Autistic Society is a guide to recognising and supporting children with autism. Single copies of the booklet are available from the National Autism Society Publications Dept, Unit 7, Arena House, 1 Temple Road, London NW2 6PG, upon receipt of a 38p A5 SAE. 